\title{
Поверхностный плазмонный резонанс \\ в изогнутом одномодовом световоде \\ с металлизированной оболочкой: экспериментальное исследование
}

\author{
(C) А.В. Дышлюк ${ }^{1,2}$, Е.В. Мицай ${ }^{2, \uparrow}$, А.Б. Черепахин ${ }^{2}$, \\ О.Б. Витрик ${ }^{1,2}$, Ю.Н. Кульчин ${ }^{1,2}$ \\ ${ }^{1}$ Дальневосточный федеральный университет, Владивосток \\ ${ }^{2}$ Институт автоматики и процессов управления ДВО РАН, Владивосток \\ ^E-mail: eugenemitsai@gmail.com
}

Поступило в Редакцию 27 декабря 2016 г.

Экспериментально исследованы процессы возбуждения плазмонного резонанса в изогнутом одномодовом волоконном световоде с металлизированной оболочкой. Показано, что при определенном сочетании радиуса изгиба световода и толщины металлической пленки реализуется сильная связь между фундаментальной и плазмон-поляритонной модой через посредство оболочечной моды шепчущей галереи, что приводит к формированию резонансного провала в спектре пропускания петли световода глубиной $\sim 30 \mathrm{~dB}$ и более. Положение провала сильно зависит от показателя преломления, что обеспечивает возможность рефрактометрических измерений со спектральной чувствительностью $\sim 5 \mu \mathrm{m} / \mathrm{RIU}$ и разрешением $\sim 4 \cdot 10^{-6}$. Пределы измерения показателя преломления определяются рабочим спектральным диапазоном и радиусом изгиба световода и для используемой в работе установки составили $1.42-1.44$.

DOI: $10.21883 /$ PJTF.2017.15.44875.16646

В настоящее время одним из магистральных направлений исследований в области биосенсорики являются оптические сенсорные системы на основе поверхностного плазмонного резонанса (ППР) [1-5]. Благодаря высокой чувствительности и отсутствию необходимости использования флуоресцентных маркеров ППР-сенсоры стали важнейшим инструментом в исследованиях биомолекулярных взаимодействий и получили широкое применение для детектирования химических и биологических аналитов [2-4]. 
Измерительные системы на основе ППР функционируют за счет возбуждения плазмон-поляритонных колебаний, распространяющихся вдоль границы раздела между металлом и диэлектриком. Наиболее распространенной схемой построения такой системы является конфигурация Кречмана, в которой металлическая пленка наноразмерной толщины наносится на одну из граней стеклянной призмы. Плазмонный резонанс возбуждается при помощи оптического пучка, падающего изнутри призмы на ее металлизированную грань под углом, превышающим угол полного внутреннего отражения. При выполнении условий фазового синхронизма падающего пучка с плазмон-поляритонной волной полное внутреннее отражение нарушается, и в угловом или частотном спектре отраженного света формируется резонансный провал, положение которого сильно зависит от показателя преломления (ПП) вблизи металлической пленки, что обеспечивает возможность высокоточных рефрактометрических измерений. Для использования такого рефрактометра в качестве биосенсора на металлическую пленку наносится слой молекуллигандов, которые могут реагировать с определенным типом молекуланалитов. Реакция ассоциации между лигандом и аналитом приводит к локальному изменению ПП вблизи пленки и может быть обнаружена по изменению положения резонансного провала в спектре регистрируемого оптического сигнала. Схема Кречмана хорошо отработана и находит широкое применение в биосенсорике, однако она плохо подходит для создания простых, компактных и недорогих ППР-биосенсоров. Поэтому большой интерес исследователей вызывают волноводные и, в частности, волоконно-оптические ППР-рефрактометры [2,6]. В таких датчиках поверхностная плазмон-поляритонная волна возбуждается излучением, распространяющимся по волоконному световоду (BC), в металлической пленке, нанесенной на его поверхность. Волоконно-оптические плазмонполяритонные рефрактометры обеспечивают такие преимущества, как варьируемая длина измерительной базы, отсутствие необходимости юстировки оптических элементов, а также возможность миниатюризации, проведения удаленных измерений и снижения стоимости биосенсорных систем. Наилучшие результаты при создании волоконнооптических ППР-рефрактометров достигаются при использовании одномодовых световодов [4-6]. Однако в таких ВС фундаментальная мода (ФМ), распространяющаяся по сердцевине, отделена от внешней среды толстым слоем оптической оболочки. Поэтому для обеспечения ее взаимодействия с металлической пленкой, как правило, требуется

Письма в ЖТФ, 2017, том 43, вып. 15 
удаление части оболочки световода химическим или механическим способом, что негативно сказывается на надежности таких датчиков и создает определенные технологические трудности.

В работах [7-9] был предложен новый подход к созданию волоконнооптических ППР-сенсоров, в котором металлическая пленка наносится непосредственно на оптическую оболочку стандартного одномодового световода. Взаимодействие направляемой по сердцевине ФМ с плазмонполяритонной модой (ППМ), распространяющейся вдоль пленки, реализуется в этом случае за счет изгиба световода - через посредство оболочечных мод шепчущей галереи (МШГ) изогнутого волоконного световода. При определенном сочетании радиуса изгиба световода и толщины металлической пленки реализуется сильная связь между ФМ, МШГ и ППМ, что обеспечивает возможность рефрактометрических измерений как в спектральном, так и в амплитудном режиме $[8,10]$. Целью настоящей работы является экспериментальное исследование данного подхода.

Схема экспериментальной установки приведена на рис. 1. С участка стандартного одномодового световода типа SMF-28 длиной $\sim 45 \mathrm{~mm}$ удаляется полимерная оболочка и на одну из его сторон наносится слой серебра наноразмерной толщины методом электронно-лучевого напыления в вакуумной напылительной системе ROBVAK ADVAVAC. Толщина наносимого слоя контролируется при помощи устройства для измерения толщины пленки Sycon STC-2002 в процессе напыления и дополнительно при помощи атомно-силового микроскопа Расіfic Nanotechnology Nano-DST после напыления. Далее металлизированный участок световода изгибается в петлю с постоянным радиусом кривизны и погружается в водный раствор глицерина с измеряемым показателем преломления $n_{3}$. Величина $n_{3}$ варьируется в пределах от 1.4 до 1.45 путем изменения концентрации глицерина и контролируется при помощи рефрактометра Аббе. Спектр пропускания световода регистрируется при помощи широкополосного источника излучения 1 (Thorlabs ASE730, $\lambda=1.5-1.65 \mu \mathrm{m}$ ) и оптического анализатора спектра 6 (Yokogawa AQ6370B). Для контроля поляризации света в исследуемой структуре используется волоконный поляризатор 2 (Thorlabs ILP1550PM-FC), который располагается непосредственно перед изогнутым чувствительным участком.

В полном соответствии с полученными ранее численными результатами [7-9] при определенном сочетании радиуса изгиба, толщины

Письма в ЖТФ, 2017, том 43, вып. 15 


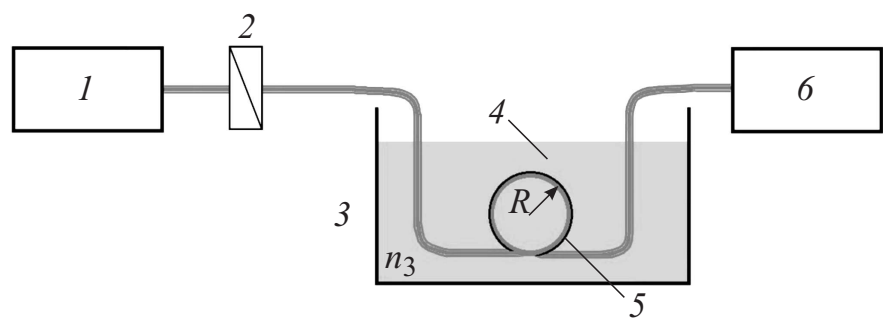

Рис. 1. Схема экспериментальной установки: 1 - широкополосный источник излучения Thorlabs ASE730, 2 - волоконный поляризатор Thorlabs ILP1550PMFC, 3 - стандартный одномодовый волоконный световод типа SMF-28, 4 жидкий раствор с измеряемым показателем преломления $n_{3}, 5-$ металлическая пленка, 6 - оптический анализатор спектра Yokogawa AQ6370B.

металлической пленки и показателя преломления $n_{3}$ в спектре пропускания исследуемой структуры формируется провал, указывающий на возбуждения ППР (рис. 2). Форма провала сильно зависит от поляризации излучения в световоде, что иллюстрируется рис. $2, a$, на котором приведены результаты измерения спектра пропускания при различных угловых положениях поляризатора. Как видно, наиболее контрастный провал, указывающий на наиболее эффективное возбуждение ППР, наблюдается при угловом положении поляризатора $0^{\circ}$, что соответствует линейной поляризации в плоскости петли чувствительного световода, при которой и проводились дальнейшие измерения.

В работах $[8,10]$ показано, что оптимальная толщина металлической пленки для исследуемой конфигурации составляет $30 \mathrm{~nm}$. Для экспериментальной проверки этого факта были изготовлены и исследованы образцы с толщиной пленки 20, 25, 30, $35 \mathrm{~nm}$. В результате экспериментов установлено, что по совокупности таких характеристик, как глубина и контрастность резонансного провала, спектральная чувствительность и диапазон измеряемого показателя преломления, оптимальная толщина пленки лежит в пределах $25-30 \mathrm{~nm}$, что хорошо согласуется со сделанной ранее оценкой.

Согласно полученным ранее численным результатам $[8,10]$, эффективная связь между фундаментальной и плазмонной модами через посредство МШГ реализуется в окрестности $\lambda \sim 1.55 \mu$ m при радиусе

Письма в ЖТФ, 2017, том 43, вып. 15 

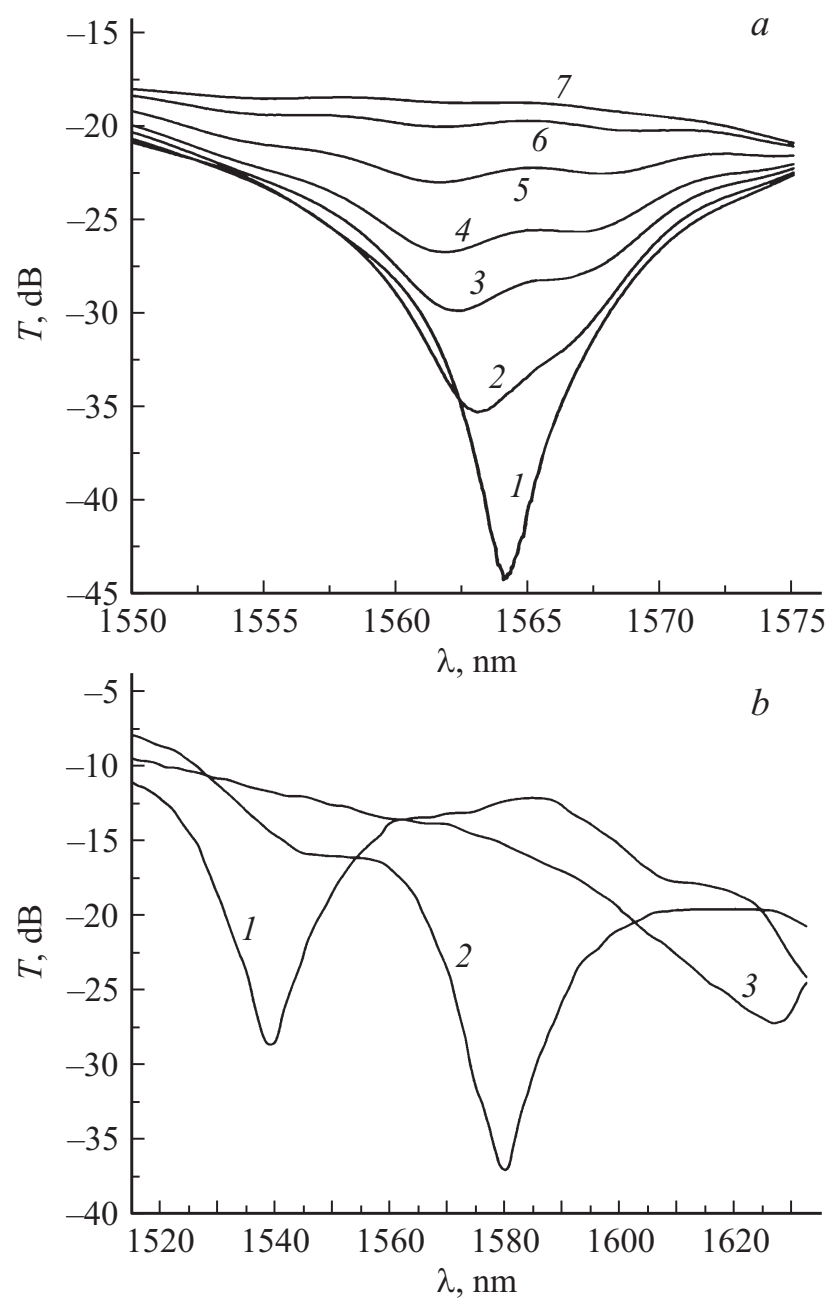

Рис. 2. Результаты измерения спектра пропускания исследуемой волноводной структуры: $a-$ при углах поляризации излучения на входе в петлю $0(1)$, $15(2), 30(3), 45(4), 60$ (5), 75 (6), 90 (7); $b$ - при различных радиусах изгиба световода: $R=7.55$ (1), 7.35 (2), $7.125 \mathrm{~mm}(3)$ (толщина металлической пленки $25 \mathrm{~nm}, n_{3} \approx 1.43$ ).

Письма в ЖТФ, 2017, том 43, вып. 15 

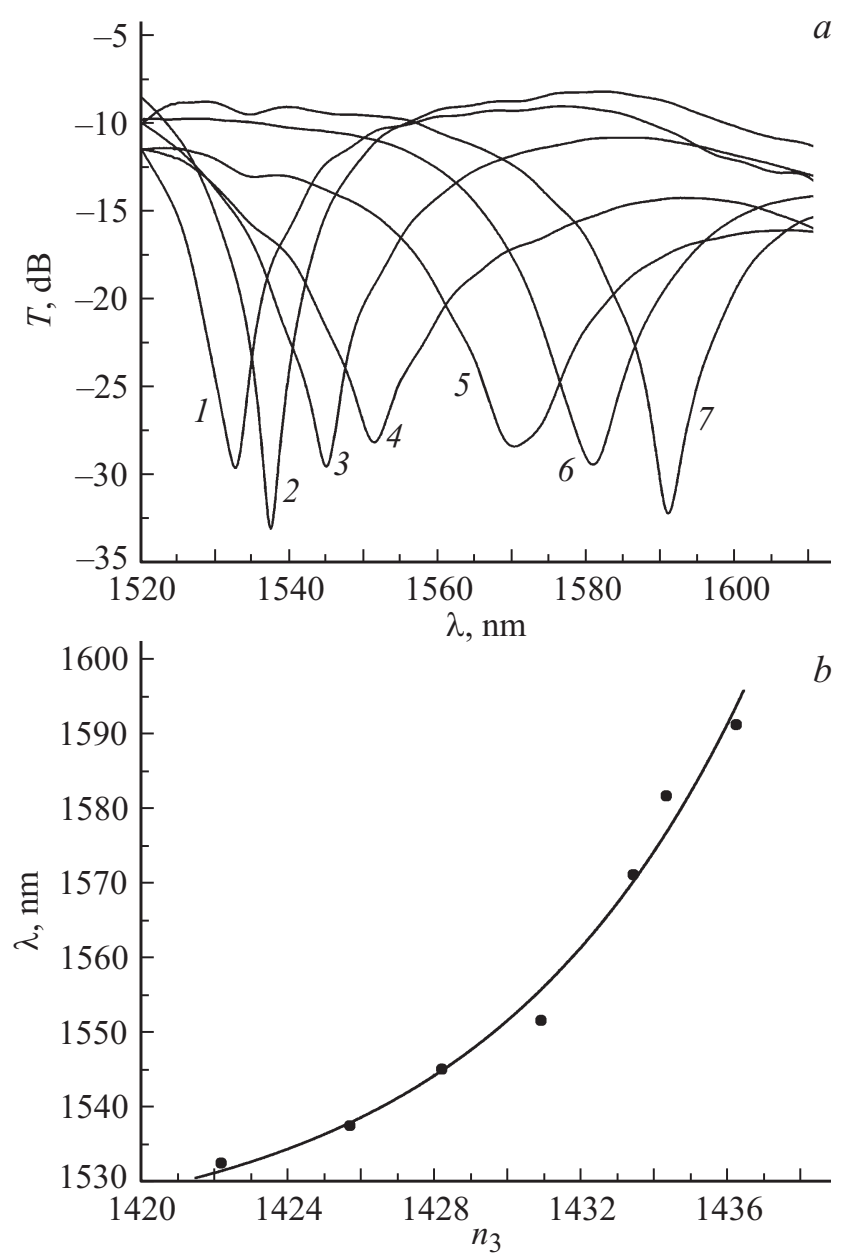

Рис. 3. Спектры пропускания (a) при $n_{3}=1.4222$ (1), 1.4257 (2), 1.4282 (3), 1.4309 (4), 1.4334 (5), 1.4343 (6), 1.4362 (7) и длины волн плазмонного резонанса $(b)$ при радиусе изгиба световода $7.55 \mathrm{~mm}$ и толщине металлической пленки $30 \mathrm{~nm}$. 
изгиба световода $\sim 7.5 \mathrm{~mm}$. Экспериментальное исследование образцов с различными радиусами изгиба в пределах от 6.9 до $8.25 \mathrm{~mm}$ полностью подтверждает численные результаты. Также можно отметить, что при увеличении радиуса изгиба длина волны плазмонного резонанса смещается в коротковолновую область с характерной величиной смещения $\sim 0.2 \mu \mathrm{m} / \mathrm{mm}$, что позволяет варьировать пределы измерения ПП в заданном спектральном диапазоне за счет изменения радиуса изгиба BC. Спектры пропускания чувствительных элементов с тремя различными радиусами изгиба при неизменном показателе преломления $n_{3}$ приведены на рис. $2, b$.

Типичные результаты измерения спектров пропускания при различных значениях показателя преломления жидкого раствора приведены на pис. 3, $a$. Как видно, резонансный провал смещается при изменении $n_{3}$, при этом зависимость длины волны плазмонного резонанса от $n_{3}$ близка к экспоненциальной (рис. $3, b$ ). Глубина резонансного провала составляет в среднем $\sim 30 \mathrm{~dB}$, диапазон измерения ПП $1.42-1.44$, спектральная чувствительность $\sim 5 \mu \mathrm{m} /$ unit. ПП. Принимая разрешение спектроанализатора равным $0.02 \mathrm{~nm}$, разрешение рефрактометрических измерений можно оценить в $\sim 4 \cdot 10^{-6}$.

Таким образом, в работе экспериментально исследованы процессы возбуждения плазмонного резонанса в изогнутом одномодовом волоконном световоде с металлизированной оболочкой вследствие сильной связи между фундаментальной и плазмон-поляритонной модами через посредство моды шепчущей галереи. Показано, что при радиусе изгиба $\sim 7.5 \mathrm{~mm}$ резонансный провал в спектре пропускания петли световода формируется в окрестности длины волны $\lambda \sim 1.55 \mu \mathrm{m}$. Типичная глубина провала при толщине металлической пленки $25-30 \mathrm{~nm}$ составляет $\sim 30 \mathrm{~dB}$, а его положение сильно зависит от показателя преломления среды вблизи пленки, что обеспечивает возможность рефрактометрических измерений со спектральной чувствительностью $\sim 5 \mu \mathrm{m} /$ Unit. ПП и разрешением $\sim 4 \cdot 10^{-6}$. Пределы измерения показателя преломления определяются рабочим спектральным диапазоном и радиусом изгиба световода и для используемой в работе установки составили 1.42-1.44.

Работа выполнена при частичной финансовой поддержке грантов ДВО РАН (15-I-4-009 о, RUSPLUS_S\&T-048) и РФФИ (16-32-00384мол_а) в рамках программы „Дальний Восток 2015-2017““ ФАНО России.

Письма в ЖТФ, 2017, том 43, вып. 15 


\section{Список литературы}

[1] Chen Y., Ming H. // Photonic Sensors. 2012. V. 2. Iss. 1. P. 37-49.

[2] Guo X. // J. Biophotonics. 2012. V. 5. Iss. 7. P. 483-501.

[3] Zijlstra P., Paulo P.M.R., Orrit M. // Nature Nanotechnology. 2012. V. 7. P. 379 382.

[4] Photonic sensing: principles and applications for safety and security monitoring / Eds G. Xiao, W.J. Bock. Wiley, 2012. 336 p.

[5] Homola J. Surface plasmon resonance based sensors. Springer series on chemical sensors and biosensors, 2006. $251 \mathrm{p}$.

[6] Gupta B.D., Verma R.K. // J. Sensors. 2009. V. 1. P. 979761.

[7] Kulchin Yu.N., Vitrik O.B., Dyshlyuk A.V., Zhou Zh. // Laser Physics. 2013. V. 23. Iss. 8. P. 085105-085109.

[8] Kulchin Yu.N., Vitrik O.B., Dyshlyuk A.V. // Opt. Express. 2014. V. 22. P. 2219622201.

[9] Дышлюк А.В., Витрик О.Б., Gиоһиi Lи, Кульчин Ю.Н. // Письма в ЖТФ. 2015. T. 41. B. 12. C. 56-63.

[10] Кульчин Ю.Р., Витрик О.Б., Дышлюк А.В., Гурбатов С.О., Gиоһиi Lu // Письма в ЖТФ. 2014. Т. 40. В. 24. С. 39-46. 